\title{
WILL NEUROSCIENCE REDEFINE MENTAL INJURY? Disability Benefit LaW, Mental Health PaRity LAW, AND DISABILITY DISCRIMINATION LAW
}

\author{
Stacey A. Tovino, JD, $\mathrm{PhD}^{*}$

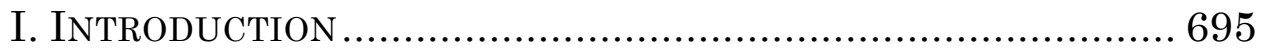

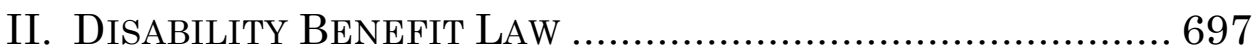 \\ III. Mental Health Parity LAW ........................................... 706 \\ IV. DiSABILITY DiSCRIMINATION LAW ................................... 720

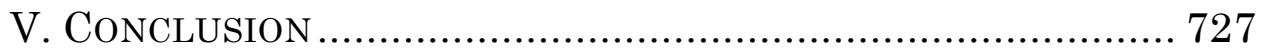

\section{INTRODUCTION}

Within the overlapping fields of neurolaw and neuroethics, scholars have given significant attention to the implications of advances in neuroscience for issues in criminal law, ${ }^{1}$ criminal procedure,${ }^{2}$ constitutional law, ${ }^{3}$ law and religion, ${ }^{4}$ tort law, ${ }^{5}$ evidence law, ${ }^{6}$ confidentiality and

* Lehman Professor of Law and Director, Health Law Program, William S. Boyd School of Law, University of Nevada, Las Vegas.

1 See Stephen J. Morse \& Adina L. Roskies, A Primer on Criminal LaW AND Neuroscience (2013).

2 See Sarah E. Stoller \& Paul Root Wolpe, Emerging Neurotechnologies for Lie Detection and the Fifth Amendment, 33 AM. J.L. \& MED. 359 (2007).

3 See Federico Gustavo Pizzetti, In Quest of Constitutional Principles of "Neurolaw,"23(3) MED. SECOLI. 963 (2011).

4 See, e.g., Steven Goldberg, Neuroscience and the Free Exercise of Religion, in LAW AND NEUROSCIENCE: CURRENT LEGAL ISSUES (2011).

5 See Betsy J. Grey, Neuroscience and Emotional Harm in Tort Law: Rethinking the American Approach to Free-Standing Emotional Distress Claims, in LAW AND Neuroscience: CurRent Legal Issues 203 (Michael Freeman ed., 2011); Shaun Cassin, Eggshell Minds and Invisible Injuries: Can Neuroscience Challenge Longstanding Treatment of Tort Injuries? 50 Hous. L. REV. 929 (2013).

6 See Stephen J. Morse, Neuroimaging Evidence in Law: A Plea for Modesty and Relevance, in NeURoImAGing IN Forensic Psychiatry: From the Clinic to the Courtroom 341 (Joseph R. Simpson ed., 2012) 
privacy law, ${ }^{7}$ protection of human subjects, ${ }^{8}$ and even the regulation of neuroscience-based technologies. ${ }^{9}$ Less attention has been paid, however, to the implications of advances in neuroscience for more traditional civil and regulatory health law issues. ${ }^{10}$ In this Article, based on my presentation made at the Indiana University Robert $\mathrm{H}$. McKinney School of Law, Hall Center for Law and Health/Indiana Health Law Review Symposium titled "Will Neuroscience Redefine Mental Injury," I wanted to provide an update regarding the ways in which neuroscience impacts three different areas within civil and regulatory health law, including public and private disability benefit law, federal mental health parity law, and federal and state disability discrimination law. ${ }^{11}$ Because the conference

(reviewing evidentiary concepts such as admissibility, relevance, and standards of proof as they relate to the possible uses of neuroimaging findings in legal proceedings").

7 See Stacey A. Tovino, Functional Neuroimaging Information: The Case for NeuroExceptionalism? 34 FLA. ST. U. L. REV. 415 (2007).

8 See, e.g., James A. Anderson et al., Neuroethical Issues in Clinical Neuroscience Research, in ETHICAL AND LEgAL Issues In NEUROLOGY: Handbook of Clinical Neurology Series 335 (James L. Bernat \& Richard Beresford eds., 2013); Stacey A. Tovino, A "Common" Proposal, 50 Hous. L. REV. 787 (2013).

9 See Henry T. Greely, Neuroscience-Based Lie Detection: The Need for Regulation, in UsING IMAGING To IDENTIFY DECEIT: SCIENTIFIC AND ETHICAL QUESTIONs 46 (Emilio Bizzi et al. eds., 2009).

10 See Stacey A. Tovino, Neuroscience and Health Law: An Integrative Approach? 42 AKRON L. REV. 469, 472 (2009) (stating, "Little attention has been paid, however, to the implications of advances in neuroscience for more traditional civil and regulatory health law issues"; exploring the ways in which neuroscience impacts a range of health, disability, and benefit law issues, including the scope of public and private health insurance benefits, the mental health parity debate, protected status under federal and state disability law, and the distribution of benefits under social security and other benefit programs).

11 My presentation brought together themes and arguments that I have made in a number of prior publications. See, e.g., Stacey A. Tovino, The DSM-5: Implications for Health Law, 2015 UTAH L. REV. (forthcoming 2015); Stacey A. Tovino, Lost in the Shuffle: How Health and Disability Laws Hurt Disordered Gamblers, 89 Tulane L. REv. 191 (2014); Stacey A. Tovino, Insurance and Parity Laws, in MENTAL Health Care Issues in America: An Encyclopedia, Vol. I, 350-57 
organizers asked the speakers to think about how advances in neuroscience provide insights that might challenge the physical-mental dichotomy, ${ }^{12}$ I particularly wanted to focus on: (1) whether the laws in these three areas provide fewer or otherwise different benefits for individuals with mental versus physical injuries, diseases, and disorders; and, if so (2) whether neuroscience is being used to confront these different benefit sets.

\section{DisABILITy Benefit LAW}

The first area on which I wanted to focus is disability benefit law. Disability benefits can be public, such as the cash disability benefits provided by the Social Security Administration (SSA) to individuals who meet the SSA's definition of disability. ${ }^{13}$ Disability benefits can also be private, such as the cash disability benefits provided by

(Michael Shally-Jensen ed., 2013); Stacey A. Tovino, A Proposal for Comprehensive and Specific Essential Mental Health and Substance Use Disorder Benefits, 38 AMERICAN J.L. \& MED. 471 (2012); Stacey A. Tovino, All Illnesses Are (Not) Created Equal: Reforming Federal Mental Health Insurance Law, 49 HARV. J. ON LEGIS. 1 (2012); Stacey A. Tovino, Further Support for Mental Health Parity Law and Mandatory Mental Health and Substance Use Disorder Benefits, 21 ANNALS Health L. 147 (2012); Stacey A. Tovino, Reforming State Mental Health Parity Law, 11 Houston J. Health L. \& Pol'Y 455 (2011); Tovino, Neuroscience and Health Law: An Integrative Approach, supra note 10, at 469; Stacey A. Tovino, The Impact of Neuroscience on Health Law, 1 NEUROETHICS 101 (2008). As such, the discussions of disability benefit law, mental health parity law, and disability discrimination law found in this Article are also available in whole or in part in the publications listed above and are taken with permission by the Author.

12 Events: Hall Center for Law and Health Conference, Will Neuroscience Redefine Mental Injury? INDIANA UNIVERSITY ROBERT H. MCKINNEY SCHOOL OF LAW (Oct. 4, 2013) available at http://mckinneylaw.iu.edu/events/current.cfm?eid=162 (stating, "Legal systems have traditionally treated physical and mental injuries differently. Advances in neuroscience provide insights that challenge this dichotomy. This multidisciplinary half-day conference will examine some of the evolving technologies used to demonstrate mental injury and explore the potential impact of this neuroscientific data in legal decision making.").

13 See infra notes 15-26. 
administrators of short- and long-term disability insurance plans to individuals who participate in such plans as a benefit of employment or who purchase such plans on the open insurance market. ${ }^{14}$

With respect to public disability benefits, Title II of the SSA provides for the payment of federal Social Security Disability Insurance (SSDI) benefits to individuals with both physical and mental disabilities. ${ }^{15}$ Indeed, the SSA defines "disability" as the "inability to engage in any substantial gainful activity by reason of any medically determinable physical or mental impairment." 16 An applicant's impairment or impairments must be "of such severity that he is not only unable to do his previous work but cannot, considering his age, education, and work experience, engage in any other kind of substantial gainful work which exists in the national economy." 17 The applicant's impairment must last or be expected to last for a continuous period of at least twelve months, or be expected to result in death. 18

The Commissioner of Social Security (Commissioner) has established a five-step sequential evaluation for determining whether an individual has a disability that qualifies for the receipt of SSDI benefits. ${ }^{19}$ First, a

14 Disability income insurance protects an individual's income. If an individual becomes unable to work due to a sickness or injury, disability income insurance provides cash benefits that the individual may use to pay for housing, food, clothing, and utilities, among other living expenses. Designed to provide financial security until the individual returns to work, disability income insurance typically pays a monthly cash benefit after an initial waiting period that is equivalent to a percentage of the individual's salary. See, e.g., Mass Mutual Financial Group, Disability Income Insurance, https://www.massmutual.com/sem/disability insurance?cm_mmc=google-_-disability_nb-_-ppc-_-60777225-VQ16-c (last visited August 11, 2015).

15 See, e.g., Locher v. Sullivan, 968 F.2d 725, 727 (8th Cir. 1992).

1642 U.S.C. $\$ 423(\mathrm{~d})(1)(\mathrm{A})(2013)$.

17 Id. $\S 423(\mathrm{~d})(2)(\mathrm{A})$.

$18 I d . \S 423(\mathrm{~d})(1)(\mathrm{A})$.

1920 C.F.R. $\S 404.1520(\mathrm{a})(4)$ (2013) (listing the five-step sequential evaluation process); id. $\S$ 416.920(a)(4) (explaining the five-step sequential evaluation process); Bowen v. Yuckert, 482 U.S. 137, 140-42 
determination is made regarding whether the individual is engaged in "substantial gainful activity." 20 If so, benefits are denied. ${ }^{21}$ Second, if the individual is not engaged in substantial gainful activity, a determination is made regarding whether the individual has a medically severe impairment or combination of impairments. ${ }^{22}$ If the individual does not have a severe impairment or combination of impairments, benefits are denied. ${ }^{23}$ Third, if the individual has a severe impairment, a determination is made regarding whether the impairment meets or equals one of a number of "listed impairments" in 20 C.F.R. part 404, subpart $\mathrm{P}$, appendix 1 . If the impairment meets or equals a "listed impairment," the individual is conclusively presumed to have a disability. ${ }^{24}$ Fourth, if the impairment does not meet or equal a "listed impairment," a determination is made regarding whether the impairment prevents the individual from performing past relevant work. If the individual can perform past relevant work, benefits are denied. ${ }^{25}$ Fifth, if the individual cannot perform past relevant work, the burden shifts to the Commissioner to show that the individual is able to perform other kinds of work. The individual is entitled to SSDI benefits only if the person is unable to perform other work. ${ }^{26}$

In addition to public SSDI benefits, private disability income insurers also offer private disability income insurance plans. These plans provide short- and long-term cash benefits to individuals who become disabled. Private disability benefits are governed not by the five-step sequential analysis set forth in federal law, above, but by the terms of the plan itself. ${ }^{27}$ As discussed in more detail

(1987) (U.S. Supreme Court opinion explaining the five-step sequential evaluation process in the context of a particular claimant).

2020 C.F.R. $\S 416.920(\mathrm{a})(4)(\mathrm{i})(2013)$.

21 Id.

22 Id. § 416.920(a)(4)(ii).

23 Id.

$24 \quad I d . \S 416.920(\mathrm{a})(4)(\mathrm{iii})$.

25 Id. $\S 416.920(\mathrm{a})(4)(\mathrm{iv})$.

26 Id. § 416.920(a)(4)(v).

27 See, e.g., McDonald v. Western-Southern Life Ins. Co., 347 F.3d 161, 163 (6th Cir. 2003) (interpreting the Western and Southern Life 
below, private disability benefit plans typically provides fewer disability insurance benefits to individuals with mental versus physical disabilities. In addition, litigants with mental disabilities are using neuroscience to confront these different benefits.

Reid v. Metropolitan Life Insurance Co. is a relatively recent case out of the Northern District of Georgia that may be used to illustrate these principles and findings. ${ }^{28}$ In Reid, defendant MetLife administered a long-term disability plan (Plan) that distinguished between physical and mental disabilities by providing long-term disability benefits for participants with permanent physical disabilities but only two years of disability benefits for participants with "Mental or Nervous Disorders or Diseases." 29 The Plan further excluded certain organic mental disorders, such as dementia, from the list of "Mental or Nervous Disorders or Diseases" and treated them like physical disabilities, eligible for long-term disability benefits. ${ }^{30}$

The claimant in the case, Ms. Reid, began in 2001 experiencing certain behavioral and other changes, including spending too much money on jewelry, difficulty in formulating words and thoughts, difficulty in processing information and making decisions, sleeping problems, and memory problems. ${ }^{31}$ A former employee of Plan sponsor International Business Machines Corporation (IBM), Ms. Reid filed a claim for long-term disability benefits in $2007 .{ }^{32}$ MetLife approved Ms. Reid's disability benefits in 2008, but only for twenty-four months. ${ }^{33}$ MetLife reasoned that Ms.

Insurance Company Flexible Benefits Plan's (Plan's) long-term disability provisions, including the Plan's definition of "Long-Term Disability or Long-Term Disabled" and noting that, pursuant to the terms of the Plan, covered employee's have the obligation to furnish proof of any long-term disabilities).

28 Reid v. Metropolitan Life Ins. Co., 944 F.Supp.2d 1279 (N.D. Ga. 2013).

29 Id. at 1282.

$30 \mathrm{Id}$.

31 Id. at $1283-85$.

32 Id. at 1285 .

33 Id. at 1289 . 
Reid suffered from a mental, not a physical, disability. ${ }^{34}$ In 2011, Ms. Reid filed a lawsuit against MetLife in the U.S. District Court for the Northern District of Georgia under the Employee Retirement Income Security Act of 1974 (ERISA). ${ }^{35}$ In the lawsuit, Ms. Reid sought to recover longterm disability benefits. ${ }^{36}$

The legal issue before the court was whether Ms. Reid had a mental diagnosis of bipolar disorder, depression, and/or attention-deficit hyperactivity disorder (ADHD), which would limit her to just twenty-four months of disability benefits, or whether her primary diagnosis was dementia, which would make her eligible for long-term disability benefits. ${ }^{37}$ Of course, Ms. Reid argued that she had dementia, a physical disability. ${ }^{38}$ MetLife took the position that Ms. Reid had bipolar disorder, a mental disability. ${ }^{39}$

In a wonderfully detailed, forty-nine page judicial opinion, District Judge Amy Totenberg thoroughly analyzed a number of medical opinions regarding the proper classification of Ms. Reid's disability. ${ }^{40}$ In Ms. Reid's earlier medical records, her treating physicians had diagnosed her with bipolar disorder, depression, and/or ADHD in light of behaviors such as spending too much money on jewelry. ${ }^{41}$ In Ms. Reid's later medical records, her treating physicians diagnosed her with dementia in light of her significant memory problems, difficulty formulating words and thoughts, and difficulty processing information and making decisions. ${ }^{42}$ MetLife's three independent physician consultants, each of whom completed a single review of Ms. Reid's file and never personally examined Ms. Reid, reported that Ms. Reid suffered from bipolar disorder. ${ }^{43}$

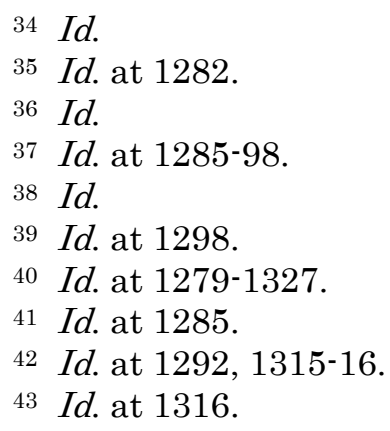


After carefully reviewing all of Ms. Reid's medical records and all of the treating and consulting physician reports, Judge Totenberg ultimately sided with Ms. Reid's later treating physicians and found that Ms. Reid had dementia, thus making her eligible for long-term disability benefits. ${ }^{44}$

Did neuroscience aid Judge Totenberg in her decision? The answer is yes. Judge Totenberg placed remarkable weight on a structural magnetic resonance image (MRI) of Ms. Reid's brain. In 2007, one of Ms. Reid's treating physicians ordered an MRI to rule out organic causes of her symptoms. ${ }^{45}$ According to the physician who interpreted the MRI, Ms. Reid had "moderate to severe cerebral atrophy, worse for the occipital lobes bilaterally." 46 Judge Totenberg relied on that interpretation; indeed, she stated that Ms. Reid's dementia was "confirmed by her neuroimaging results showing cerebral atrophy." ${ }^{7}$ Judge Totenberg ultimately held that MetLife's failure to consider the MRI as evidence of dementia was not only de novo wrong but also arbitrary and capricious. 48

The Reid case is an excellent illustrator of how private disability benefit plans distinguish between physical and mental disabilities and provide fewer benefits for individuals with mental disabilities. The case also illustrates how litigants and judges are using neuroimaging to confront the somewhat artificial distinctions between physical and mental disabilities. I chose the Reid case for discussion not only for these reasons, but also because Judge Totenberg actually addressed the legal distinctions between physical and mental disabilities. Indeed, Judge Totenberg quoted the preface to the American Psychiatric Association's (APA) then-current edition of the Diagnostic

44 Id. at $1315-16$.

45 Id. at 1285.

46 Id. at $1286-87$.

47 Id. at 1323.

48 Id. at 1280, 1315-16 (stating, "The court finds Dr. Stallings' opinions, based on an eight-year treating relationship with Plaintiff and Dr. Carstens's reports, the MRI results, and repeated neurological testing results to be far more reliable than the opinions of Met-Life's three IPC's whose opinions were each based on a single file review."). 
and Statistical Manual of Mental Disorders (DSM-IV) to explain that:

[T] he term mental disorder unfortunately implies a distinction between "mental" disorders and "physical" disorders that is a reductionistic anachronism of mind/body dualism. A compelling literature documents that there is much "physical" in "mental" disorders and much "mental" in "physical" disorders. The problem raised by the term "mental" disorders has been much clearer than its solution, and, unfortunately, the term persists in the title of DSM-IV because we have not found an appropriate substitute. ${ }^{49}$

That is, Judge Totenberg correctly recognized that the Plan was forcing her to make a decision regarding whether Ms. Reid had a physical or mental disability even though the APA itself believes that there is much physical in mental and much mental in physical and that no definition of "mental disorder" could adequately specify precise boundaries between the physical and mental.

I also liked how Judge Totenberg recognized that a clinical diagnosis of a mental disorder under the DSM-IV generally is not sufficient to establish the existence for legal purposes of a mental disability:

When the DSM-IV categories, criteria, and textual descriptions are employed for forensic purposes, there are significant risks that diagnostic information will be misused or misunderstood. These dangers arise because of the imperfect fit between the questions of ultimate concern to the law and the information contained in a clinical diagnosis. In most situations, the clinical diagnosis of a

49 Id. at 1305-06. The fifth edition of the Diagnostic and Statistical Manual ("DSM-5") is the current edition but the DSM-IV was current at the time of the facts giving rise to the Reid case. 
DSM-IV mental disorder is not sufficient to establish the existence for legal purposes of a "mental disorder," "mental disability," "mental disease," or "mental defect." In determining whether an individual meets a specified legal standard (e.g., for competence, criminal responsibility, or disability), additional information is usually required beyond that contained in the DSM-IV diagnosis. This might include information about the individual's functional impairments and how these impairments affect the particular abilities in questions. ${ }^{50}$

Because the MetLife Plan at issue defined mental disability entirely in terms of the DSM-IV, ${ }^{51}$ Judge Totenberg based her legal decision on whether Ms. Reid met the manual's diagnostic criteria for dementia.52 Judge Totenberg correctly recognized, however, that the APA designed the manual for use by clinicians in the clinic, not for judges and lawyers in the courtroom. ${ }^{53}$ Stated another way, Judge Totenberg seemed to be suggesting that private disability plans' heavy reliance on the DSM-IV might be displaced given the different objectives of law and medicine.

The Reid case involved a claim for private disability benefits. Claims for public disability benefits are somewhat different. As discussed above, federal law does not on its face discriminate against claimants with mental disabilities by providing less comprehensive disability income insurance benefits for individuals with mental disabilities compared to

$50 \quad I d$. at 1307.

51 See id. at 1282 (referencing the Plan provision stating that "Mental or Nervous Disorder or Disease means a medical condition which meets the diagnostic criteria set forth in the most recent edition of the Diagnostic And Statistical Manual of Mental Disorders as of the date of Your Disability.").

52 Id. at $1308-11$.

53 Id. at 1306 ("The diagnostic categories, criteria, and textual descriptions are meant to be employed by individuals with appropriate clinical training and experience in diagnosis. It is important that DSMIV not be applied mechanically by untrained individuals."). 
individuals with physical disabilities. ${ }^{54}$ As applied, however, federal law can make it more difficult for individuals who claim that they have a mental disability to prove that disability because federal law requires the impairment to be "medically determinable." As one might imagine, historically it has been easier for claimants to use radiologic, laboratory, and other diagnostic tests to prove a physical disability compared to a mental disability. ${ }^{55}$ For example, a computed tomography (CT) and other brain scans can be used to diagnose certain types of physical (traumatic) brain injuries. On the other hand, individuals with major depression, bipolar disorder, and schizophrenia historically have not had access to a similar radiologic diagnostic tool.

However, advances in neuroimaging may be making it slightly easier for individuals to prove their mental disabilities. For example, SSDI claimants are now offering neuroimaging evidence as confirmatory evidence of their mental disabilities and some courts are accepting the confirmation provided by such evidence. For example, one SSDI claimant with alcohol dependence submitted to the SSA a neuroimage that was interpreted to reveal alcoholic cortical atrophy, which correlated with dementia and impaired capacity to work. ${ }^{56}$ The reviewing court agreed that the neuroimage was confirmatory of the claimant's mental disability claim and clinically correlated with his abnormal mental status examination, functional incapacity, and neuropsychological testing. ${ }^{57}$

5442 U.S.C. $§ 423(\mathrm{~d})(1)(\mathrm{A})$ (2015) (defining "disability" as the "inability to engage in any substantial gainful activity by reason of any medically determinable physical or mental impairment") (emphasis added).

55 See, e.g., William B. Smith et al., Proving the Invisible Injury: Making an Impact With Video Settlement Documentaries in Traumatic Brain Injury Cases, Forum, Mar.-Apr. 2010, at 27.

56 See Joseph R. Simpson, NEURoIMAging In ForEnsic Psychiatry: From the Clinic to the Courtroom 206, fig. 12.4 (Joseph R. Simpson ed., 2012).

57 Id. 


\section{MENTAL HEALTh PARITY LAW}

Like the private disability plans discussed in Part II, private health insurance policies and plans also (at least historically) have distinguished between physical and mental illnesses and have provided inferior insurance benefits for mental illnesses. That is, private health insurance policies and plans have either completely excluded treatments and services for mental disorders from insurance coverage or have provided less comprehensive health insurance coverage for mental disorders. ${ }^{58} \mathrm{I}$ teach at the William S. Boyd School of Law at the University of Nevada, Las Vegas (Boyd), located a few blocks from the famous Las Vegas Strip, and at Boyd we think a lot about the legal rights of individuals with gambling disorders as well as the legal responsibilities of casinos vis-à-vis such individuals. Historically, many private health plans have provided no insurance coverage of treatments and services for gambling disorder 59 as well as many similar mental disorders. ${ }^{60}$

In the past two decades, health insurance law has eliminated most, but still not all, of these mental health benefit disparities. After reviewing recent improvements in mental health parity law, I will use the case of gambling disorder to illustrate how advances in neuroscience are being used to confront remaining mental health benefit disparities.

58 See Stacey A. Tovino, A Proposal for Comprehensive and Specific Essential Mental Health and Substance Use Disorder Benefits, 38 AM. J.L. \& MED. 471, 475 (2012); Stacey A. Tovino, All Illnesses Are (Not) Created Equal: Reforming Federal Mental Health Insurance Law, 49 HARV. J. ON LEGIS. 1, 3 (2012).

59 See, e.g., Tovino, Lost in the Shuffle, supra note 11, at nn. 127131 (providing examples of health insurance policies and plans that have provided no or inferior health insurance benefits for individuals with gambling disorder).

60 Elsewhere, I detailed how litigants have tried to confront these artificial distinctions in health insurance policies and plans in order to obtain comprehensive health insurance benefits. See, e.g., Stacey A. Tovino, All Illnesses Are (Not) Created Equal, 49 HARV. J. ON LEGIS. 1, 31-5 (2010). 
The federal government took its first step towards establishing mental health parity on September 26, 1996, when President Bill Clinton signed the federal Mental Health Parity Act (MHPA) into law. ${ }^{61}$ As originally enacted, MHPA prohibited large group health plans that offered medical and surgical benefits as well as mental health benefits from imposing more stringent lifetime and annual spending limits on their offered mental health benefits. ${ }^{62}$ For example, MHPA would have prohibited a large group health plan from imposing a $\$ 20,000$ annual cap or a $\$ 100,000$ lifetime cap on mental health care if the plan had no annual or lifetime caps for medical and surgical care or if the plan had higher caps, such as a $\$ 50,000$ annual cap or a $\$ 500,000$ lifetime cap, for medical and surgical care. ${ }^{63}$

The problem with MHPA was that its application and scope were very limited. As originally enacted, MHPA only regulated insured and self-insured group health plans of large employers, then defined as those employers that employed an average of fifty-one or more employees. ${ }^{64}$ MHPA thus did not apply to the group health plans of small employers. ${ }^{65}$ MHPA also did not apply to individual health plans, the Medicare Program, Medicaid non-managed care plans, or any self-funded, non-federal governmental plan whose sponsor opted out of MHPA. ${ }^{66}$ Finally, MHPA

61 See Mental Health Parity Act, Pub. L. No. 104-204, 110 Stat. 2944 (1996), Title VII, $§ 701$ et seq. [hereinafter MHPA] (codified as amended at 29 U.S.C. $\S 1185 a$ (2006 \& Supp. IV 2010); 42 U.S.C. § 300gg-26 (2006 \& Supp. IV 2010)).

62 See id. $\S 712(\mathrm{a})(1),(2)$.

63 See id.

64 See id. (applying in each case to "a group health plan (or health insurance coverage offered in connection with such a plan ...")).

65 See id. $\S 712(\mathrm{c})(1)(\mathrm{A})$, (B) (exempting from MHPA application group health plans of small employers; defining small employers as those who employed an average of at least 2 but not more than fifty employees on business days during the preceding calendar year and who employs at least two employees on the first day of the plan year).

66 See, e.g., 42 U.S.C. $\S 300 \mathrm{gg}-21(\mathrm{a})(2)(\mathrm{A})$ (permitting sponsors of self-insured non-federal governmental health plans to opt out of particular federal requirements); 45 C.F.R. $\S \quad$ 146.180(a)(1)(v) (permitting sponsors of self-insured non-federal governmental health plans to opt out of federal mental health parity requirements). 
contained an "increased cost" exemption for covered group health plans or health insurance coverage offered in connection with such plans if the application of MHPA resulted in an increase in the cost under the plan of at least one percent. 67 By November 1998, over two years following MHPA's enactment, only four plans across the United States had obtained exemptions due to cost increases of one percent or more. 68

In terms of its substantive provisions, MHPA was neither a mandated offer nor a mandated benefit law; that is, nothing in MHPA required a large group health plan to actually offer or provide any mental health benefits. ${ }^{69}$ Thus, health plans were free after the enactment of MHPA to simply not provide any benefits for gambling disorder or any other mental health condition. ${ }^{70}$ As originally enacted, MHPA also was not a comprehensive parity law because it expressly excluded from protection individuals with substance use and addictive disorders, such as alcohol use disorder and other drug use disorders. ${ }^{71}$ (MHPA did not specifically mention gambling disorder one way or another.) In addition, MHPA did not require parity between medical and surgical benefits and mental health benefits in terms of deductibles, copayments, coinsurance, inpatient day limitations, or outpatient visit limitations. ${ }^{72}$

67 MHPA, supra note 61 , at $\S 712(\mathrm{c})(2)$.

68 See Colleen L. Barry, The Political Evolution of Mental Health Parity, 14 HARV. Rev. Psychiatry 185, 187 (2006) [hereinafter Barry, Political Evolution].

69 See MHPA, supra note 61, § 712(b)(1) (stating, "Nothing in this section shall be construed as requiring a group health plan (or health insurance coverage offered in connection with such a plan) to provide any mental health benefits ...").

70 See id.

71 See id. § 712(e)(4) (stating, "The term 'mental health benefits' means benefits with respect to mental health services, as defined under the terms of the plan or coverage (as the case may be), but does not include benefits with respect to treatment of substance abuse or chemical dependency.")

72 See id. $\S 712(\mathrm{~b})(2)$ (stating, "Nothing in this Section shall be construed .... as affecting the terms and conditions (including cost sharing, limits on numbers of visits or days of coverage, and requirements relating to medical necessity) relating to the amount, 
Because of these limitations, President George W. Bush expanded MHPA twelve years later by signing into law the Paul Wellstone and Pete Domenici Mental Health Parity and Addiction Equity Act of 2008 (MHPAEA). ${ }^{73}$ MHPAEA built on MHPA by expressly protecting individuals with substance-related and addictive disorders and by imposing comprehensive parity requirements on large group health plans. ${ }^{74}$ In particular, MHPAEA provided that any financial requirements (including deductibles, copayments, coinsurance, and other out-of-pocket expenses) 75 and treatment limitations (including inpatient day and outpatient visit limitations) 76 that large group health plans imposed on mental health and substance use disorder benefits must not be any more restrictive than the predominant financial requirements and treatment limitations imposed by the plan on substantially all medical and surgical benefits. ${ }^{77}$ MHPAEA thus would have prohibited large group health plans from imposing higher deductibles, copayments, or coinsurances, or lower inpatient day and outpatient visit maximums, on individuals seeking care for gambling disorder or any other mental health or

duration, or scope of mental health benefits under the plan or coverage . ..").

73 See Mental Health Parity and Addiction Equity Act of 2008, Pub. L. No. 110-343, 122 Stat. 3881, Title V, Subtitle B, §§ 511-512 [hereinafter MHPAEA] (codified as amended at 29 U.S.C. $\S 1185 \mathrm{a}$ and 42 U.S.C. $§ 300 \mathrm{gg}-26)$.

74 See id. §512(a)(4) (adding a new definition of 'substance use disorder benefits'); id. §512(a)(1) (regulating the financial requirements and treatment limitations that are applied to both mental health and substance use disorder benefits).

75 See id. § 512(a)(1) (including within the definition of "financial requirements" deductibles, copayments, coinsurance, and out-of-pocket expenses).

76 See id. (including within the definition of "treatment limitations" limits on the frequency of treatment, number of visits, days of coverage, and other similar limits on the scope or duration of treatment).

77 See id. (requiring both financial requirements and treatment limitations applicable to mental health and substance use disorder benefits to be no more restrictive than the predominant financial requirements and treatment limitations applied to substantially all physical health benefits covered by the plan). 
substance use disorder listed in the current edition of the DSM or the International Classification of Diseases (ICD). ${ }^{78}$

Like MHPA, MHPAEA's application and scope were very limited. As originally enacted, MHPAEA only regulated insured and self-insured group health plans of large employers, defined as those employers that employ an average of fifty-one or more employees. ${ }^{79}$ MHPAEA, like MHPA, did not apply to small group health plans, individual health plans, the Medicare Program, Medicaid non-managed care plans, or any self-funded, non-federal governmental plans whose sponsors had opted out of MHPAEA. ${ }^{80}$ In terms of its substantive provisions,

78 See, e.g., 78 Fed. Reg. 68240, 68286 (Nov. 13, 2013) (adopting 45 C.F.R. $\S 146.136$, a federal regulation implementing MHPAEA that requires a plan's definition of "mental health benefits" and "substance use disorder benefits" to be "consistent with generally recognized independent standards of current medical practice (for example, the most current version of the Diagnostic and Statistical Manual of Mental Disorders (DSM), the most current version of the ICD, or State guidelines").

79 MHPAEA, supra note $73, \S 512(\mathrm{a})(1)$ (applying only to group health plans or health insurance coverage offered in connection with such plans).

80 See Ctrs. for Consumer Info. \& Ins. Oversight, The Mental Health Parity and Addiction Equity Act, U.S. DeP'T HEALTh \& HuMAN SERVS., (providing, "MHPAEA does not apply directly to small group health plans."); id. ("[Medicare, Medicaid] are not issuers of health insurance. They are public health plans through which individuals obtain health coverage. ... Medicaid benchmark benefit plans [however] ... require compliance with certain requirements of MHPAEA."); id. ("Non-Federal governmental employers that provide self-funded group health plan coverage to their employees (coverage that is not provided through an insurer) may elect to exempt their plan (opt-out) from the requirements of MHPAEA . . .."); Colleen L. Barry et al., A Political History of Federal Mental Health and Addiction Insurance Parity, 88 MiLbanK Q. 404, 407 (2010) (explaining that the MHPAEA applies to Medicare Advantage coverage offered through a group health plan, Medicaid managed care, the State Children's Health Insurance Program, and state and local government plans, but not Medicaid nonmanaged care plans); Letter from Cindy Mann, Dir. of the Ctr. for Medicaid and CHIP Servs. (CMCS), Ctrs. for Medicare \& Medicaid Servs., Dep't of Health \& Human Servs., to State Health Officials 2 (Nov. 4, 2009) ("The MHPAEA requirements apply to Medicaid only insofar as a State's Medicaid agency contracts with one or more managed care organizations (MCOs) or Prepaid Inpatient Health Plans 
MHPAEA also was neither a mandated offer nor a mandated benefit law; that is, nothing in MHPAEA required a covered group health plan to actually offer or provide any gambling disorder benefits or other mental health benefits. ${ }^{81}$ Like MHPA, MHPAEA also contained an "increased cost" exemption for covered group health plans and health insurance coverage offered in connection with such plans, but under MHPAEA the amount of the required cost increase increased, at least for the first year. ${ }^{82}$ That is, a covered plan that could demonstrate a cost increase of at least two percent in the first plan year and one percent in each subsequent plan year of the actual total costs of coverage with respect to medical and surgical benefits and mental health and substance use disorder benefits would be eligible for an exemption from MHPAEA for such year. ${ }^{83}$ MHPAEA required determinations of exemption-qualifying cost increases to be made and certified in writing by a

(PIHPs), to provide medical/surgical benefits as well as mental health or substance use disorder benefits . . . MHPAEA parity requirements do not apply to the Medicaid State plan if a State does not use MCOs or PIHPs to provide these benefits.").

81 See MHPAEA, supra note $73, \S 512(\mathrm{a})(1)$ (regulating only those group health plans that offer both physical health and mental health benefits); Substance Abuse and Mental Health Services Administration, Implementation of the Mental Health Parity and Addiction Equity Act, (MPHAEA), U.S. DEP'T HEALTH \& HumaN SERV., http://www.samhsa.gov/health-financing/implementation-mentalhealth-parity-addiction-equity-act (noting that "Self-insured non-federal government employee plans can opt out of the federal parity law"; further stating that, "The requirements of parity do not apply to ... [s]mall employer plans created before March 23, 2010 ... ; Churchsponsored plans and self-insured plans sponsored by state and local governments; Retiree-only plans; TriCare; Medicare; Traditional Medicaid (fee-for-service, non-managed care)"; Centers for Medicare \& Medicaid Services, The Ctr. for Consumer Info. \& Ins. Oversight, The Mental Health Parity and Addiction Equity Act, U.S. DeP'T HeAlth \& HUMAN SERVs., http://cms.hhs.gov/CCIIO/Programs-andInitiatives/Other-Insurance-Protections/mhpaea_factsheet.html (noting the same limitations).

82 See MHPAEA, supra note 73, § 512(a)(3) (establishing new cost exemption provisions).

$$
{ }^{83} I d \text {. }
$$


qualified and licensed actuary who in good standing belongs to the American Academy of Actuaries. ${ }^{84}$

Before President Obama signed the health care reform bill into law, then, mental health insurance benefits were regulated by MHPA as expanded by MHPAEA as well as by more stringent state law. ${ }^{85}$ That is, unless a more stringent state law required a health plan to provide gambling disorder benefits or other mental health benefits (which state law usually did not), a health plan was not required to provide such benefits.

In late March 2010, President Obama responded to this limitation by signing the Patient Protection and Affordable Care Act (PPACA) and the Health Care and Education Reconciliation Act (HCERA) into law (as consolidated, the Affordable Care Act (ACA)). 86 Best known for its controversial individual health insurance mandate, ${ }^{87} \mathrm{ACA}$ has two sets of provisions that relate to mental health parity and mandatory mental health and substance use disorder benefits. Upheld by the U.S. Supreme Court on June 28, 2012,88 these two sets of provisions eliminate some of the limitations of MHPA and MHPAEA.

The first set of ACA provisions extends MHPA's and MHPAEA's mental health parity provisions to the individual and small group health plans offered on and off

$84 I d$.

85 See Stacey A. Tovino, Reforming State Mental Health Parity Law, 11 Hous. J. HeAlTh L. \& Pol'y 455, at Parts I.A.-I.D. (2011) (describing the patchwork of state mental health parity law and providing examples of state laws that are more and less stringent than federal law).

86 See Patient Protection and Affordable Care Act (ACA), Pub. L. No. 111-148, 124 Stat. 119 (2010), amended by Health Care and Education Reconciliation Act, Pub. L. No. 111-152, 124 Stat. 1029 (2010) [hereinafter, ACA].

87 ACA § 1501(a) (adding to the Internal Revenue Code: "An applicable individual shall for each month beginning after 2013 ensure that the individual, and any dependent of the individual who is an applicable individual, is covered under minimum essential coverage for such month.").

88 Nat'l. Fed'n. of Indep. Bus. v. Sebelius, 132 S. Ct. 2566 (2012). 
the health insurance exchanges. ${ }^{89}$ Now, many individual and small group health plans that previously discriminated against individuals with gambling disorder and other mental health conditions through higher deductibles, copayments, and coinsurance rates, as well as lower inpatient day and outpatient visit limitations, must comply with MHPA and MHPAEA. 90

The second set of relevant ACA provisions requires certain health plans to actually provide mental health and substance use disorder benefits. That is, ACA now requires individual and small group health plans, ${ }^{91}$ exchange-offered qualified health plans, ${ }^{92}$ State basic health plans, ${ }^{93}$ and Medicaid benchmark and Medicaid benchmark plans ${ }^{94}$ to offer "mental health and substance use disorder services, including behavioral health treatments" in addition to nine other categories of essential health benefits (EHBs).95 Unfortunately, not every individual with health insurance will benefit from these ten required EHB categories because

89 ACA, supra note 86, § 1311(j) (entitled, “Applicability of Mental Health Parity") (stating, "[MHPAEA] shall apply to qualified health plans in the same manner and to the same extent as such section applies to health insurance issuers and group health plans."); 42 U.S.C. $\S 300 g g-26$ (2015) (entitled "Parity in Mental Health and Substance Use Disorder Benefits'); ACA, supra note 86, § 1563(c)(4) (identifying the conforming and technical changes that will be made to former 42 U.S.C. $300 g^{-5} 5$ (current 42 U.S.C. $\left.§ 300 \mathrm{gg}-26\right)$ ); Historical and Statutory Notes for former 42 U.S.C. $\S 300 \mathrm{gg}-5$ (noting that former 42 U.S.C. $\S 300 \mathrm{gg}-5$ was transferred to 42 U.S.C. § 300gg-26). See also Ctr. for Consumer Info. \& Ins. Oversight, Essential Health Benefits Bulletin, U.S. DEP'T Health \& Human Servs., 1, 12 (Dec. 16, 2011) [hereinafter EHB Bulletin] ("The Affordable Care Act also specifically extends MHPAEA to the individual market.").

90 See supra note 89.

91 ACA, supra note 86, § 1201 (adding new Public Health Service Act $§ 2707$ (a), codified at 42 U.S.C. $\S 300$ gg-6(a)).

92 Id. § 1301(a)(1)(B) (adding new 42 U.S.C. § 18021(a)(1)(B)).

93 Id. $\S 1331(\mathrm{e})$. Individuals eligible for State basic health plan coverage include individuals who are not eligible for Medicaid and whose household income falls between 133 and 200 percent of the federal poverty line for the family involved as well as low-income legal resident immigrants. ACA, supra note 86, § 1331(e).

94 Id. $§ 2001(\mathrm{c})(3)$ (adding new 42 U.S.C. $\S 1396 \mathrm{u}^{-7}(\mathrm{~b})(5)$ ).

$95 \quad I d . \S 1302(\mathrm{~b})(1)(\mathrm{A})-(\mathrm{J})$. 
grandfathered health plans, large group health plans, and self-insured health plans are exempt from the requirement to provide the ten EHB categories. ${ }^{96}$

For those health plans that must provide benefits within the ten EHB categories, the statutory EHB requirements are unclear as to whether particular benefits, such as gambling disorder benefits, are required. As a result, the federal Department of Health and Human Services (HHS) issued final regulations implementing ACA's EHB requirements (Final Regulations) on February 25, 2013.97 These Final Regulations permit states to select a benchmark plan ${ }^{98}$ that provides coverage for the ten EHB categories, including mental health and substance use

${ }^{96}$ Interim Final Rules for Group Health Plans and Health Insurance Coverage Relating to Status as a Grandfathered Health Plan Under the Patient Protection and Affordable Care Act, 75 Fed. Reg. 34538, 34562 (June 17, 2010) [hereinafter, Interim Final Grandfather Rules] (adding new 29 C.F.R. § 2590.715-1251(a), which defines 'grandfathered health plan coverage' as "coverage provided by a group health plan, or a health insurance issuer, in which an individual was enrolled on March 23, 2010."); id. at 34559 (explaining that section 2707 of the Public Health Service Act does not apply to grandfathered health plans); id. at 34563 (adding new 29 C.F.R. § 2590.715-1251(c)(1) (stating, "[T]he provisions of PHS Act sections . . . 2707 . . . do not apply to grandfathered health plans.")); DEP'T LABOR, EMPLOYEE BENEFITS SECURITY ADMIN., Application of the New Health Reform Provisions of Part A of Title XXVII of the PHS ACT to GRANDFATHERED Plans 1 (June 17, 2010) (explaining that ACA's essential benefit package requirement is not applicable to grandfathered plans); See Inst. OF MED., EssEnTIAL HEAlth Benefits: Balancing Coverage AND Cost (2011), at 1-8, 1-9, 1-10 and Box 1-2 (listing the health plan settings to which ACA's EHB requirement do not apply); Sara Rosenbaum et al., The Essential Health Benefits Provisions of the Affordable Care Act: Implications for People with Disabilities, 3 Commonwealth Fund 1, 3 (Mar. 24, 2011) ("The act exempts large-group health plans, as well as self-insured ERISA plans and ERISA-governed multiemployer welfare arrangements not subject to state insurance law, from the essential benefit requirements.").

97 Patient Protection and Affordable Care Act, Pub. L. No. 111-148, 124 Stat. 119 (2010); Standards Related to Essential Health Benefits, Actuarial Value, and Accreditation; Final Rule, 78 Fed. Reg. 12834 (Feb. 25, 2013) [hereinafter Final EHB Regulations].

98 Final EHB Regulations, supra note 97, at 12866 (adopting 45 C.F.R. $§ 156.100)$. 
disorder services, ${ }^{99}$ that will serve as a reference plan for health plans in the state. According to the Final Regulations, health plans in the state that are required to provide the ten EHB categories shall provide health benefits that are substantially equal to those provided by the state's benchmark plan, including the benchmark plan's covered benefits and excluded benefits. ${ }^{100}$ Thus, the question of whether a particular health insurance policy or plan must provide benefits for a particular mental disorder after the $\mathrm{ACA}$ requires an analysis of whether the plan is required to provide the ten EHB categories as well as the content of each state's selected benchmark plan.

And this is where neuroscience is coming into play. In an article recently published in the Tulane Law Review, I analyzed whether state benchmark plans, including Nevada's benchmark plan, covered treatments and services for gambling disorder. 101 The State of Nevada's benchmark plan is the Health Plan of Nevada Point of Service Group 1 C XV 500 HCR Plan. ${ }^{102}$ If, as written on March 31, 2012, the Nevada Benchmark Plan included gambling disorder benefits, then individual, small group, and other health plans in the State of Nevada that are required to provide the ten EHB categories must provide gambling disorder benefits in years 2014 and 2015. ${ }^{103}$ On the other hand, if the Nevada Benchmark Plan did not include gambling disorder benefits on March 31, 2012, then gambling disorder

99 Id. at 12866 (adopting 45 C.F.R. § 156.110(a)(5)).

100 Id. at 12867 (adopting 45 C.F.R. $§ 156.115(\mathrm{a})$ ).

101 Tovino, Lost in the Shuffle, supra note 11.

102 See Nevada EHB Benchmark Plan, CTR. For MedicAre \& MEDICAID SERV., available at http://www.cms.gov/CCIIO/ Resources/Data-Resources/Downloads/nevada-ehb-benchmark-plan.pdf; Letter from Scott J. Kipper, Comm'r of Ins., Div. of Ins., State of Nev., to Sec'y Kathleen Sebelius, U.S. Dep't of Health \& Human Services (Dec. 14, 2012), available at http://doi.nv.gov/uploadedFiles/doinvgov/_publicdocuments/Healthcare-Reform/12.14.12_kipper_letter_re_ehb.pdf

(identifying Nevada's benchmark plan selection).

103 See e-mail from Glenn Shippey, Nev. Div. of Ins., to Stacey Tovino, Lincy Professor of Law, William S. Boyd Sch. of Law, Univ. of Nev., Las Vegas (Oct. 2, 2013, 4:12 PM) (on file with author) [hereinafter Shippey Email] (explaining the application of the EHB requirements in the State of Nevada). 
benefits are not essential health benefits in the State of Nevada and individuals with gambling disorder will not have gambling disorder benefits in years 2014 and 2015 unless their health plans voluntarily include such benefits 104 or unless the states in which they live independently fund gambling disorder treatments and services. 105

On March 31, 2012, the Nevada Benchmark Plan included coverage for outpatient and inpatient treatment of certain mental health conditions, including substancerelated conditions (such as alcohol use disorder and the drug use disorders). ${ }^{106}$ On March 31, 2012, however, the Nevada Benchmark Plan excluded coverage for a class of mental health conditions known as the "impulse control disorders." 107 Because the then-current (2012) edition of the DSM-the DSM-IV-TR-classified "pathological gambling" as an impulse control disorder, the result was that the Nevada Benchmark Plan excluded coverage for treatments for gambling disorders for years 2014 through 2016 . That is, through the end of 2016, Nevada residents will not benefit from any mandatory gambling disorder benefits and will only have benefits to the extent their health plans voluntarily provide gambling disorder benefits or their states independently fund gambling disorder treatments.

104 See Essential Health Benefits (Updated), HeALTH AFFaIRS, HeAlth POLICY BRIEFs (May 2, 2013), http://www.healthaffairs.org/ healthpolicybriefs/brief.php?brief_id=91 (noting that HHS has indicated that the benchmark plan approach may be changed in 2016 and in future years based on evaluation and feedback).

105 See, e.g., Bo J. BERnhaRd ET AL., Evaluation of State-Funded Problem Gambling Treatment Programs in Nevada, available at https://www.yumpu.com/en/document/view/35015311/evaluation-of-

state-funded-problem-gambling-treatment-programs- ${ }^{-} \quad$ (discussing problem gambling treatments that are partially or fully supported by the State of Nevada).

106 See Ctr. For Medicare \& Medicaid SERv., Nevada EHB BENCHMARK PLAN 3 , rows 26 and 27, available at http://www.cms.gov/CCIIO/Resources/Data-

Resources/Downloads/nevada-ehb-benchmark-plan.pdf.

107 See Shippey e-mail, supra note 103 (noting the Nevada Benchmark Plan's exclusion of "impulse control disorders"). 
However, due to neuroimaging, the story may be very different for years 2017 and beyond. That is, advances in the neuroscientific understanding of certain mental disorders have resulted in their reclassification in the DSM. Let us use gambling disorder as an example. First recognized by the APA in the DSM-III in 1980,108 a condition then-named "pathological gambling" was classified within the "Disorders of Impulse Control Not Elsewhere Classified."109 Characterized with reference to an individual's "chronic and progressive failure to resist impulses to gamble and gambling behavior that compromises, disrupts, or damages personal, family, or vocational pursuits," pathological gambling was believed by the APA to have an adolescent age of onset and to be more common among males than females and more common in the fathers of males and in the mothers of females. ${ }^{110}$ Predisposing factors were thought to include loss of parent by death, separation, divorce, or desertion before the individual turned fifteen years of age; inappropriate parental discipline; exposure to gambling activities as an adolescent; a high family value on material and financial symbols; and lack of family emphasis on saving, planning, and budgeting. ${ }^{111}$ Pathological gambling remained in the "Disorders of Impulse Control Not Elsewhere Classified"

108 The word "gambling" does not appear anywhere in the first or second editions of the DSM. See Am. Psychiatric Ass'N, Diagnostic AND Statistical MANUAL OF MENTAL Disorders (1952) [hereinafter DSM-I]; Am. Psychiatric Ass'n, Diagnostic and Statistical Manual OF Mental Disorders With SPECIAL SupPlement ON Plans FOR REVISION (1965) [hereinafter DSM-I-R]; and AM. PsYCHIATRIC Ass'N, Diagnostic AND StatisticAl MANUAL OF Mental Disorders (2d ed. 1968) [hereinafter DSM-II]. See also Randy Stinchfield, Reliability, Validity, and Classification Accuracy of a Measure of DSM-IV Diagnostic Criteria for Pathological Gambling, 160 AM. J. PsYCHIATRY 180, 180 (2003) (stating, "Pathological gambling was formally recognized as a mental disorder by APA in DSM-III.").

109 Am. Psychiatric Ass'n, Diagnostic and Statistical Manual OF MENTAL DisORDERs 291-93 (3d ed. 1980) [hereinafter DSM-III].

110 Id. at 292.

111 Id. 
sections of the DSM-III-R (1987), the DSM-IV (1994), and the DSM-IV-TR (2000). ${ }^{112}$

The DSM-5, published in May 2013,113 took pathological gambling in a new direction. First, the DSM-5 re-named the condition "gambling disorder,"114 reflecting concerns that the adjective "pathological" is pejorative and reinforces the social stigma associated with problem gambling. ${ }^{115}$ Second, the DSM-5 re-classified gambling disorder and placed it as the sole disorder within the "Non-SubstanceRelated Disorders" section within the larger "SubstanceRelated and Addictive Disorders" chapter. ${ }^{116}$ Now, gambling disorder follows alcohol use disorder, cannabis use disorder, opioid use disorder, stimulant use disorder, and tobacco use disorder, among other substance-related and addictive disorders. ${ }^{117}$

The change in gambling disorder's classification reflected neuroimaging evidence that "gambling behaviors activate [neural] reward systems similar to those activated by drugs of abuse and produce[s] behavioral symptoms that appear comparable to those produced by the substance use disorders."118 Charles O'Brien, M.D., who chaired the

112 Tovino, Lost in the Shuffle, supra note 11, at text accompanying notes 20-34.

113 Am. Psychiatric Ass'N, Diagnostic and Statistical Manual OF Mental Disorders 585 (5th ed. 2013) [hereinafter DSM-5]; See Nancy M. Petry et al., An Overview of and Rationale for Changes Proposed for Pathological Gambling in the DSM-5, 30 J. GAMBLING STUD. 493, 495 (2013).

114 See DSM-5, supra note 113.

115 See Christine Reilly \& Nathan Smith, The Evolving Definition of Pathological Gambling in the DSM-5, NAT'L CTR. FOR RESPONSIBLE GAMing White PAPER 4 (May 2013); Petry et al., supra note 113, at 406 ("Over the past three decades, the term 'pathological' has become outdated and pejorative. Thus, the name of the disorder will be altered in DSM-5 to 'gambling disorder.").

116 DSM-5, supra note 113 , at 481.

117 Id. at 483-585; Constance Holder, Behavioral Addictions Debut in Proposed DSM-V, 327 SCIEnce 935 (Feb. 19, 2010) (noting that gambling disorder would be the only disorder in the behavioral, or nonsubstance, portion of the substance-related and addictive disorders category).

118 DSM-5, supra note 113, at 481; See also Kenneth Blum et al., Reward Deficiency Syndrome: Addictive, Impulsive and Compulsive 
Substance-Related Disorders Work Group for the DSM-5, explained:

The idea of a non-substance-related addiction may be new to some people, but those of us who are studying the mechanisms of addiction find strong evidence from animal and human research that addiction is a disorder of the brain reward system, and it doesn't matter whether the system is repeatedly activated by gambling or alcohol or another substance. ... . In functional brain imaging-whether with gamblers or drug addicts-when they are showed video or photograph cues associated with their addiction, the same brain areas are activated. ${ }^{119}$

In summary, the current Nevada Benchmark Plan includes coverage for outpatient and inpatient treatment of substance-related and addictive conditions. If this benchmark plan is selected again for years 2017 and beyond, ${ }^{120}$ the result would be that insurance coverage of substance-related and addictive conditions, now including gambling disorder, would be required by federal law. Stated slightly differently, advances in the neuroscientific understanding of gambling disorder will have positively impacted the disorder's insurance coverage.

Disorders-Including Alcoholism, Attention-Deficit Disorder, Drug Abuse and Food Bingeing-May Have a Common Genetic Basis, 84 AMERICAN SCIENTIST 132, 140 (1996) (noting the affinities between pathological gambling and alcohol and drug abuse).

119 Mark Moran, Gambling Disorder to Be Included in Addictions Chapter, PsYchIATRIC NEWs (Oct. 22, 2014), available at http://psychnews.psychiatryonline.org/doi/full/10.1176\%2Fappi.pn.2013. 4b14, archived at http://perma.cc/95QZ-P8Z7.

120 See 80 Fed. Reg. 10750, 10812-13 (Feb. 27, 2015) (requiring each state to select a new base-benchmark plan for the 2017 plan year based on a 2014 plan meeting the requirements of 45 C.F.R. $\S 156.110$; explaining, "[W]e are finalizing the re-codification of part of $\S 156.120$ as proposed, as well as our proposal to allow issuers to design a plan that is substantially equal to the newly selected 2014 benchmark plan for the 2017 plan year."). 


\section{DISABILITY DiSCRIMINATION LAW}

The final area of the law on which I wanted to focus is disability discrimination law. Like public disability benefit law, disability discrimination law does not generally discriminate against individuals with mental disabilities. However, disability discrimination law does except certain conditions, including a handful of mental health conditions, from the definition of disability. Although litigants have not yet used advances in neuroscience to confront these exceptions, I predict that they will shortly.

As background, a range of anti-discrimination protections and accommodations are available to qualified individuals who have physical and mental disabilities under a variety of federal and state laws. Signed into law by President Richard Nixon on September 26, 1973, Section 504 of the Rehabilitation Act prohibits employers and organizations that receive federal financial assistance from discriminating on the basis of disability against qualified individuals with disabilities. ${ }^{121}$ The original Americans with Disabilities Act (ADA), signed into law by President George H.W. Bush on July 26, 1990, prohibits certain employers, state and local government agencies, and places of public accommodation from discriminating on the basis of disability against qualified individuals with disabilities. ${ }^{122}$ The ADA Amendments Act of 2008 (ADAAA), signed into law by President George W. Bush on September 25, 2008, clarifies that the ADA's definition of disability should be broadly construed in favor of individuals with physical and mental impairments who seek protection and generally

121 Rehabilitation Act of 1973, § 504, Pub. L. No. 93-112, 87 Stat. 355 (Sept. 26, 1973) (codified at 29 U.S.C. $\S \S ~ 701-718)$ (providing, "No otherwise qualified handicapped individual in the United States . . . solely by reason of his handicap, be excluded from the participation in, be denied the benefits of, or be subjected to discrimination under any program or activity receiving Federal financial assistance.").

122 Americans with Disabilities Act of 1990, Pub. L. No. 101-336, 104 Stat. 327 (July 26, 1990) (codified at 42 U.S.C. $\S \S 12101-12150$ [hereinafter ADA]). 
shall not require extensive analysis. ${ }^{123}$ State laws such as the California Fair Housing and Employment Act also provide individuals with protection from harassment and discrimination in the contexts of housing and employment because of physical or mental disability. ${ }^{124}$ One theme underlying these federal and state statutes is that it is wrong to discriminate against individuals because of their physical and mental disabilities and that it is right to accommodate them to help them participate more fully in society. 125

To determine whether an individual is entitled to protection under one of these statutes, each statute's definition of "disability" must be examined.126 For example, the original ADA defined a disability as, "with respect to an individual -- (A) a physical or mental impairment that substantially limits one or more of the major life activities of such individual; (B) a record of such an impairment; or (C) being regarded as having such an impairment." 127 The regulations implementing the original ADA defined "physical or mental impairment" to include, in relevant

123 The ADA Amendments Act of 2008, Pub. L. No. 110-325, 122 Stat. 3553 (Sept. 25, 2008) (codified at $42 \S$ U.S.C. 12101) [hereinafter ADAAA].

124 CAL. Gov'T Code $§ 12940$ (West 2015); CAL. Gov’T Code $§ 12955$ (West 2015).

125 See, e.g., Timothy P. Ward, Needing a Fix: Congress Should Amend the Americans with Disabilities Act of 1990 to Remove a Record of Addiction as a Protected Disability, 36 RUTGERs L.J. 683, 719 (2005) (stating that "[i]mplicit in Congress's legitimate goal of protecting the disabled from discrimination is the idea that discrimination against disabled persons is unfair because it is wrong to treat a person differently based on circumstances or conditions over which he has no control.").

126 The definitions of "disability" that are used by the SSA and by private disability income insurance benefit insurers, discussed in supra Part I, are different than the definitions used by federal and state antidiscrimination laws and are not applicable here. See, e.g., Labit v. AkzoNobel Salt, Inc., No. 99-30047, 2000 U.S. App. LEXIS 41195, at *1-4 (5th Cir. Feb. 7, 2000) (distinguishing Social Security disability determinations from ADA disability determinations and noting, for example, that Social Security disability determinations do not take into account workplace accommodations).

127 ADA $\S 3(2)(\mathrm{A})-(\mathrm{C})$ (emphasis added). 
part, "any physiological disorder, or condition, ... affecting . . . [the] neurological [system]" or "[a]ny mental or psychological disorder, such as mental retardation, organic brain syndrome, emotional or mental illness, and specific learning disabilities."128 These regulations also defined "major life activities" to include "functions such as caring for oneself, performing manual tasks, walking, seeing, hearing, speaking, breathing, learning, and working." 129 Note that both the ADA and its implementing regulations used the phrase "physical or mental impairment." Like public disability benefit law, then, individuals with mental impairments appear to be expressly included in the ADA's general protections.

Title I of the ADA, relating to employment, prohibited covered entities from "discriminat[ing] against a qualified individual with a disability ${ }^{130}$ because of the disability of such individual in regard to job application procedures, the hiring, advancement, or discharge of employees, employee compensation, job training, and other terms, conditions, and privileges of employment."131 Several different portions of the original ADA's implementing regulations promulgated by the Equal Employment Opportunity Commission (EEOC), ${ }^{132}$ a lengthy set of interpretive guidelines, ${ }^{133}$ and

12829 C.F.R. § 1630.2(h)(1)-(2) (emphasis added) (pre-ADAAA regulations establishing the definition of physical or mental impairment); See also Equal Employment Opportunity for Individuals with Disabilities, 56 Fed. Reg. 35,726 (July 26, 1991) (codified at 29 C.F.R. $\S 1630.2(\mathrm{~h})(1)-(2))$.

129 Id. § 1630.2(i)); See also Equal Employment Opportunity for Individuals with Disabilities, supra note 128.

130 Title I of the ADA defined a qualified individual with a disability as "an individual with a disability who, with or without reasonable accommodation, can perform the essential functions of the employment position that such individual holds or desires.” ADA $§ 101(8)$.

131 ADA $\S 102(\mathrm{a})$.

132 See, e.g., 29 C.F.R. $\S 1630.2(\mathrm{~h})(2)$ (2007) (pre-ADAAA regulations clarifying that a protected mental impairment includes "any mental or psychological disorder, such as mental retardation, organic brain syndrome, emotional or mental illness, and specific learning disabilities.").

133 See, e.g., Appendix to 29 C.F.R. § 1630 -- Interpretive Guidance on Title I of the Americans with Disabilities Act (pre-ADAAA 
hundreds of judicial opinions ${ }^{134}$ were dedicated to distinguishing the conditions that would and would not result in an individual's protection under the statute.

For example, Title I of the original ADA clarified that the term "qualified individual with a disability" did not include "any employee or applicant who is currently engaging in the illegal use of drugs, when the covered entity acts on the basis of such use." 135 However, Title I of the original ADA also clarified that an individual who meets the following criteria must not be excluded from protection:

(1) has successfully completed a supervised drug rehabilitation program and is no longer engaging in the illegal use of drugs, or has otherwise been rehabilitated successfully and is no longer engaging in such use;

(2) is participating in a supervised rehabilitation program and is no longer engaging in such use; or

(3) is erroneously regarded as engaging in such use, but is not engaging in such use ..."136

Importantly, Title I of the ADA also specifically excluded "compulsive gambling" (as well as kleptomania and pyromania) from the definition of disability. ${ }^{137}$ The exclusion is complete; that is, individuals who have

Interpretive Guidance providing, "It is important to distinguish between conditions that are impairments and physical, psychological, environmental, cultural, and economic characteristics that are not impairments. . . . The definition, likewise, does not include characteristic predisposition to illness or disease. . . . [Similarly,] [t]he definition does not include common personality traits such as poor judgment or a quick temper where these are not symptoms of a mental or psychological disorder. Environmental, cultural, or economic disadvantages such as poverty, lack of education or a prison record are not impairments.").

134 Search on WestlawNext database returned 1597 cases in the Notes of Decision section of 42 U.S.C. $§ 12102$ (2015). Search conducted on June 2, 2015 (listing cases that distinguish protected disabilities from unprotected conditions).
135 ADA $\S 104(\mathrm{a})$.
136 Id. § 104(b).
137 Id. § 511(b)(2). 
successfully completed a gambling rehabilitation program and are no longer engaged in gambling are not excepted from the exclusion (i.e., are not protected) in the same way that individuals who have successfully completed a drug rehabilitation program and are no longer engaged in the use of drugs are excepted. Case law interpreting the original $\mathrm{ADA}$ confirms that individuals with gambling disorder are not protected. 138

The ADA's complete exclusion of compulsive gambling from the definition of disability may be due to its original classification as an impulse control disorder. As discussed in Part III of this Article, the APA initially classified pathological gambling as an impulse control disorder (alongside kleptomania, ${ }^{139}$ pyromania, ${ }^{140}$ and intermittent explosive disorder ${ }^{141}$ ) in the DSM-III (1980). As late as 2000 , in the DSM-IV-TR (2000) - ten years after the enactment of the original ADA - the APA continued to classify pathological gambling as an impulse control disorder (still alongside kleptomania, pyromania, intermittent explosive disorder, and trichotillomania $\left.{ }^{142}\right) .{ }^{143}$

138 See, e.g., Labit, 2000 U.S. App. LEXIS 41195, at *2 (stating, "Congress specifically excluded compulsive gambling as a disability under the Act."); See also Trammell v. Raytheon Missile Systems, 721 F. Supp.2d 876, 878-82 (D. Ariz. 2010) (stating, "Congress expressly excluded compulsive gambling, along with various sexual disorders, kleptomania, pyromania, and psychoactive substance use disorders resulting from current drug use, from the ADA's definition of disability"; and rejecting the plaintiff's theory that compulsive gambling is synonymous with depression "given the ADA's express exclusion of compulsive gambling as a disability").

139 Kleptomania, according to the DSM-III, is the recurrent failure to resist impulses to steal objects not for immediate use or their monetary value. DSM-III, supra note 109, at 293.

140 Pyromania, according to the DSM-III, is the recurrent failure to resist impulses to set fires and intense fascination with setting fires and seeing them burn. Id. at 294.

141 Intermittent explosive disorder, according to the DSM-III, is characterized by several discrete episodes of loss of control of aggressive impulses that result in serious assault or destruction of property. Id. at 295.

142 Trichotillomania, according to the DSM- 5 , is the recurrent pulling out of one's hair for pleasure, gratification, or relief of tension that results in noticeable hair loss. DSM-5, supra note 113, at 251. 
Not until May 2013, in the DSM-5, did the APA rename the condition gambling disorder and re-classify it as a "NonSubstance-Related Disorder" within the "Substance-Related and Addictive Disorders." 144 Gambling disorder certainly may have suffered in its treatment by Congress due to the disorder's linkage to the other impulse control disorders. That is, stealing, fire setting, and hair-pulling may not have "sounded" in disability as much as other traditional neurological and psychiatric conditions.

With respect to other health conditions that were not specifically excluded from protection, the question of whether individuals with such conditions would be protected by the ADA required a case-by-case analysis of whether the condition constituted a physical or mental impairment and, if so, whether the impairment substantially limited a major life activity. ${ }^{145}$ The case law interpreting the original ADA made clear that individuals with episodic symptoms, as well as individuals who took medications that controlled their symptoms, were not protected individuals with disabilities. In Johnson v. North Carolina Department of Health and Human Services, for example, the U.S. District Court for the Middle District of North Carolina held that a county social worker with bipolar disorder and migraines was not substantially limited in the major life activity of working and, therefore, did not qualify as an individual with a disability under the

143 See AmERICAN Psychiatric Association, Diagnostic AND Statistical Manual of Mental Disorders 674 (4th ed. - Text Revision 2000) [hereinafter DSM-IV-TR].

144 DSM-5, supra note 113 , at 585.

145 See, e.g., Head v. Glacier Northwest Inc., 413 F.3d 1053, 1057-61 (9th Cir. 2005) (finding that genuine issues of material fact existed as to whether an employee diagnosed with depression or bipolar disorder was substantially limited in major life activity of interacting with others, due to such things as avoiding crowds and not leaving his house for weeks); McGeshick v. Principi, 357 F.3d 1146, 1150 (10th Cir. 2004) (interpreting substantial limitation to mean that the impairment prevents or severely restricts the individual from doing activities that are of central importance to most people's daily lives and that the impairment's impact must be permanent or long term). 
ADA. ${ }^{146}$ Similarly, in Doebele v. Sprint/United Management Company, the U.S. Court of Appeals for the Tenth Circuit held that an employee who was diagnosed with bipolar disorder, attention deficit disorder, and hypothyroidism was not significantly limited in her ability to communicate with others and, therefore, did not qualify as an individual with a disability under the ADA. 147 More broadly, in Olson v. General Electric Astrospace, the U.S. Court of Appeals for the Third Circuit clarified that neither multiple personality disorder nor a sleep disorder constituted a disability without proof that the disorder also substantially limited a major life activity. ${ }^{148}$

By 2008, Congress had grown weary of the limitations placed by courts on the classes of individuals eligible to receive protections under the ADA. ${ }^{149}$ On September 25, 2008, President George W. Bush signed the ADAAA into law. ${ }^{150}$ The ADAAA continued to use a three-prong definition of disability including, with respect to an individual: (1) a physical or mental impairment that substantially limits one or more major life activities of such individual; (2) a record of such an impairment; or (3) being regarded as having such an impairment. ${ }^{151}$ The ADAAA further stated that the definition of disability in the ADAAA "shall be construed in favor of broad coverage of individuals ... to the maximum extent permitted by the terms of [the ADAAA]."152

Even after the enactment of the ADAAA, however, Congress continued to exclude certain conditions from the definition of disability. Today, the ADA as amended continues to exclude "compulsive gambling, kleptomania, or pyromania" from the definition of disability. ${ }^{153}$ Many state

146 Johnson v. North Carolina Dep't of Health \& Human Servs., 454 F. Supp.2d 467, 473 (M.D.N.C. 2006).

147 Doebele v. Sprint/United Mgmt. Co., 342 F.3d 1117, 1131-35 (10th Cir. 2003).

148101 F.3d 947, 952-53 (3d Cir. 1996).

149 ADAAA $\S 2(\mathrm{a})-(\mathrm{b})$.

150 Id. $\S 1$.

151 Id. $\S 3$ (emphasis added).

152 Id.

153 See 42 U.S.C. $§ 12211(b)(2)(2015)$. 
laws also continue to exclude individuals with gambling disorder from protected status. For example, the California Fair Employment and Housing Act, ${ }^{154}$ which was designed to "protect and safeguard the right and opportunity of all persons to seek, obtain, and hold employment without discrimination or abridgment on account of" physical disability, mental disability, and other indicators, 155 continues to exclude "compulsive gambling" from the definition of both "mental disability" 156 and "physical disability." 157

Unlike private disability benefit law and health insurance law, in which neuroscience is being used to confront mental disability benefit and mental health insurance disparities, I have not yet seen a lobbyist, litigant, or other stakeholder try to use the current neuroscientific understanding of gambling disorder, discussed at supra Part III, to remove the gambling disorder exclusion in disability discrimination law. However, I do think that a stakeholder could make a good argument that gambling disorder should be treated more like alcohol-use disorder and other substance-use disorders in federal and state disability discrimination law.

\section{CONCLUSION}

In summary, private disability benefit law, health insurance law, and certain exceptions within federal and state disability discrimination law do discriminate against individuals with mental health conditions. In addition, it may be more difficult for individuals to prove their mental

154 CAL. GOV’T CODE $§ 12900-12996$ (2015).

155 Id. at $\S 12920$.

156 Id. § 12926(j) (stating, "Mental disability' does not include sexual behavior disorders, compulsive gambling, kleptomania, pyromania, or psychoactive substance use disorders resulting from the current unlawful use of controlled substances or other drugs.").

157 Id. $\S 12926(\mathrm{~m})(6)$ (stating, "Physical disability' does not include sexual behavior disorders, compulsive gambling, kleptomania, pyromania, or psychoactive substance use disorders resulting from the current unlawful use of controlled substances or other drugs."). 
health conditions under public disability benefit law. Further, neuroscience is being used to confront distinctions in private disability benefit law and health insurance law, and to help prove mental disabilities in public disability benefit law. Stakeholders are not yet using neuroscience to confront exceptions from disability discrimination laws that discriminate against individuals with certain mental health conditions, including gambling disorder. However, I do anticipate that stakeholders may use neuroscience towards this end in the near future. 